\title{
Compact and portable digitally controlled device for testing footwear materials: Technical note
}

\author{
James G. Foto, BSME, CPed \\ National Hansen's Disease Programs, Paul W. Brand Biomechanics Laboratory, Baton Rouge, LA
}

\begin{abstract}
Little or no practical decision-making data are available to the foot-care provider regarding the selection of orthotic materials used in therapeutic footwear. A device for simulating in-shoe forefoot conditions for the testing of orthosis materials is described. Materials are tested for their effectiveness by evaluating and comparing stress-strain and dynamic compression fatigue characteristics. The device, called the Cyclical Compression Tester (CCT), has been optimized for size, simplicity of construction, and cost. Application of the device ranges from the clinician deciding the useful life of single- and multidensity orthosis materials to the researcher characterizing materials for finite-element analysis modeling. This real-time CCT device and custom user interface combine to make an evaluation tool useful for testing how the pressure distribution of in-shoe materials changes over time in therapeutic footwear for those with peripheral neuropathy at risk for foot injury.
\end{abstract}

Key words: Cyclical Compression Tester, diabetic footwear, finite element analysis, materials testing, orthosis, orthotic, peripheral neuropathy, pressure distribution, rehabilitation, therapeutic footwear.

\section{INTRODUCTION}

Sensory neuropathy and abnormal levels of mechanical stress are considered the primary causes of plantar foot ulceration and are common factors in the pathway to lower-limb amputation [1-3]. Localized prominent areas resulting from skeletal deformities are most affected by mechanical stress. Therapeutic footwear is thought to be a frontline defense modality for reducing harmful stress and thus preventing the occurrence or recurrence of neuropathic plantar ulceration [4-8]. Equally important is the foot/shoe interface, namely the orthosis, which has been shown to effectively reduce forefoot pressures when compared with a shoe without an orthosis [9-13].

Currently, little or no practical decision-making data are available to the foot-care provider regarding the selection of orthotic materials used in therapeutic footwear. Manufacturer and other commercial information only provide static data, such as apparent density, durometer, and compression set. The ideal dynamic properties to test for when determining in-shoe material characteristics are mechanical stress (a perpendicular force applied over area), strain (the change of thickness to the original thickness ratio), and fatigue (the material breakdown after repeated cyclical stress). From these properties, most applicable material characteristics can be derived,

Abbreviations: ASTM = American Society for Testing and Materials, CCT $=$ Cyclical Compression Tester, DC $=$ direct current, $\mathrm{DCF}=$ dynamic compression fatigue, $\mathrm{LP}=$ linear potentiometer, $\mathrm{MP}=$ Microcel Puff, $\mathrm{P}=$ Poron, $\mathrm{P} 1=$ Plastazote 1 , P2 = Plastazote 2, PLC = programmable logic controller, $\mathrm{S}-\mathrm{S}=$ stress-strain, UDSP = user-defined set point.

Address all correspondence to James G. Foto, BSME, CPed; National Hansen's Disease Programs, Paul W. Brand Biomechanics Laboratory, 1770 Physicians Park Dr, Baton Rouge, LA 70816; 225-756-3739; fax: 225-756-3737. Email: ifoto@hrsa.gov

DOI: 10.1682/JRRD.2007.07.0111 
such as hardness, durability, compressibility, and resilience. For determination of these material properties, a benchtop device would provide essential data for an objective material-selection pathway that is still very much a subjective determination.

Previous laboratory bench studies have examined various materials under rapid impact loading, primarily simulating heel-strike during running [14-18]. The diabetic forefoot, where ulceration occurs most often [1,1920], is better modeled quasistatistically or at very low rates of loading [21]. The diabetic forefoot is modeled mathematically, suggesting no impact during the foot-flat to toe-off phase of gait. Dynamic compression testing using a determined number of cycles, loading rate, and pressures equivalent to the conditions found in the footwear forefoot better characterizes the useful service life of materials [22].

Several investigators have examined forefoot loading conditions by using custom bench devices capable of measuring mechanical stress and strain. Using a modified procedure from the American Society for Testing and Materials (ASTM) designated ASTM D573-67, Campbell et al. compared the compression properties of a set of materials, $2.85 \mathrm{~cm}$ standardized diameter, by using a normalized log linear method after a series of 250,000 cycles, at a rate of $1 \mathrm{~Hz}$ and pressure of $294 \mathrm{kPa}$ [23]. Brodsky et al. compared commonly used orthosis materials under cyclical loading of 5,000 cycles per day for 2 days with the original compression characteristics of the materials [24]. While the previous authors used noninstrumented analog devices, Sanders et al. and Petre et al. used digitally controlled devices capable of quantitatively monitoring stress-strain (S-S) mechanical behavior for each cycle over the period tested [25-26]. No previous studies, however, have reported fatigue, which is called dynamic compression fatigue (DCF) in this article. Additionally, no previous studies have demonstrated materials testing using a compact, portable benchtop device that is digitally controlled, programmable, repeatable, and cost-effective.

In this technical note, a device for simulating in-shoe forefoot conditions for the testing of orthosis materials is described. The simulation will test materials for their effectiveness by evaluating and comparing the S-S and DCF characteristics. The device has been optimized for size, simplicity of construction, and cost. The device is called the Cyclical Compression Tester (CCT).

\section{METHODS}

A single CCT device measures $15.2 \mathrm{~cm}$ wide $\times 34.3 \mathrm{~cm}$ long $\times 15.2 \mathrm{~cm}$ high and weighs approximately $4 \mathrm{~kg}$ (Figure 1). The unit has a $12.7 \times 27.9 \mathrm{~cm}$ footprint and is designed to sit on a desktop within $1 \mathrm{~m}$ of a computer with Microsoft Windows XP (Redmond, Washington) operating system and the custom user interface (LabVIEW, National Instruments Corp; Austin, Texas).

All structural components of the CCT are made from nominal size aluminum and steel items for lower cost and ease of assembly. The extent of machine shop work for assembly is limited to cutting, drilling, and tapping followed by the attachment of the ball screw actuator (Industrial Devices Corp; Rockford, Illinois), load cell (Transducer Techniques; Temecula, California), linear potentiometer (LP) (UniMeasure; Corvallis, Oregon), and rubber footings. The baseplate is $15.2 \times 30.5 \times 1.3 \mathrm{~cm}$ thick aluminum reinforced on the underside with two $2.5 \times$ $27.9 \times 1.3 \mathrm{~cm}$ steel channels. The aluminum tailpiece, where the load cell and rear compression plate are anchored, is $3.8 \times 2.5 \times 5.1 \mathrm{~cm}$ and the two $1.6 \mathrm{~cm}$-thick compression plates are parted from $5.7 \mathrm{~cm}$-diameter aluminum round stock.

The electronic control system interfaces between the computer and the CCT (Figure 2). A strain gauge input module (Dataforth; Tucson, Arizona) amplifies the signal from the load cell in-line with the actuator, which is fed to a programmable logic controller (PLC) (International Parallel Machines, Inc; New Bedford, Massachusetts)

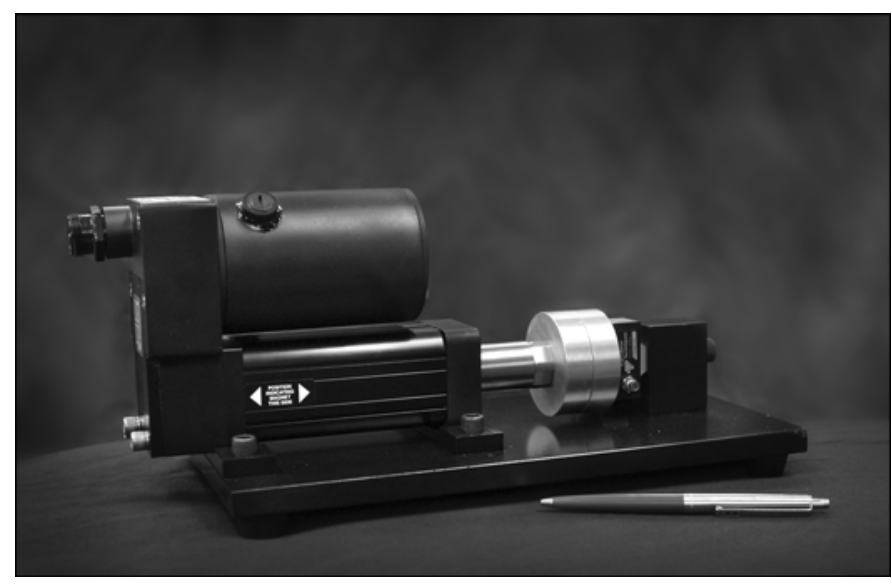

Figure 1.

Cyclical Compression Tester device for evaluating orthosis materials used in therapeutic footwear. 


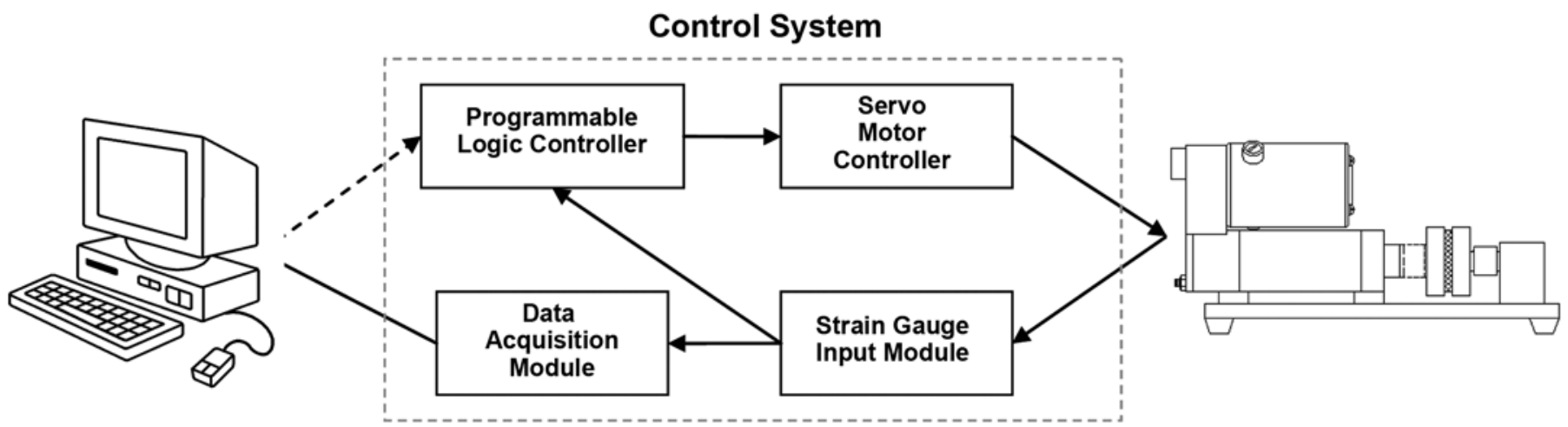

Figure 2.

Cyclical Compression Tester electronic control system diagram.

monitoring minimum and maximum force predetermined by the user. When minimum or maximum force is sensed, the PLC sends a proportional analog direct current (DC) voltage to the servo motor controller (Advanced Motion Controls; Camarillo, California) for direction and speed of the actuator, thus producing the cyclical motion. The PLC enables the system to respond to the cyclical events with predictable results rather than depending on the laptop computer's operating system, which cannot guarantee immediate response because of its multitasking nature. The principal components of the CCT device are listed in the Table.

Data acquisition is accomplished by monitoring the in-line force and position of the actuator head. These two variables occupy analog voltage input channels in the data acquisition module (National Instruments Corp) in which real-time control and feedback are obtained through the customized user interface (Figure 3). The user determines the frequency with which data are

Table.

Electronic componentry used in Cyclical Compression Tester device.

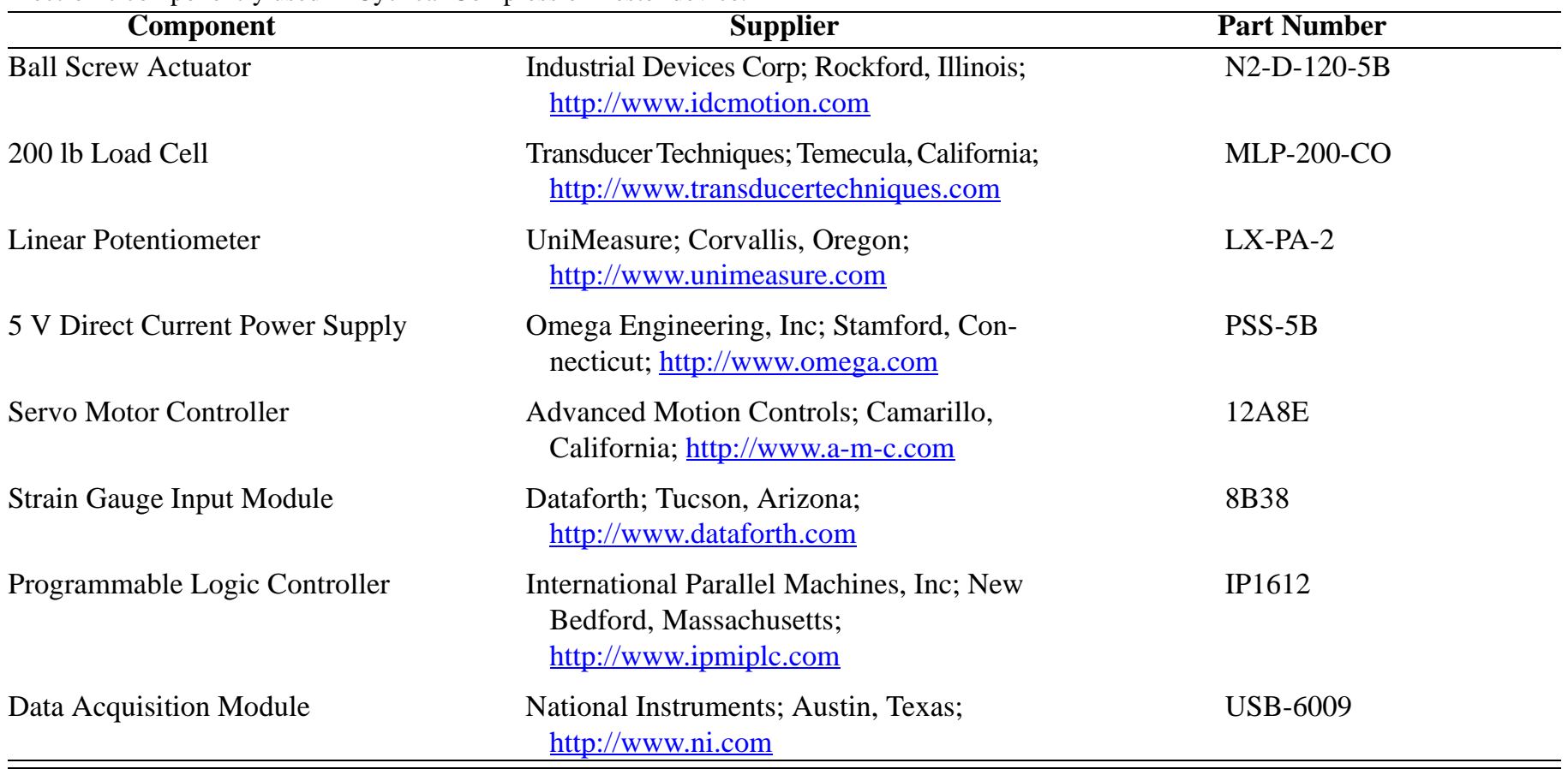




\section{Cyclical Compression Tester}
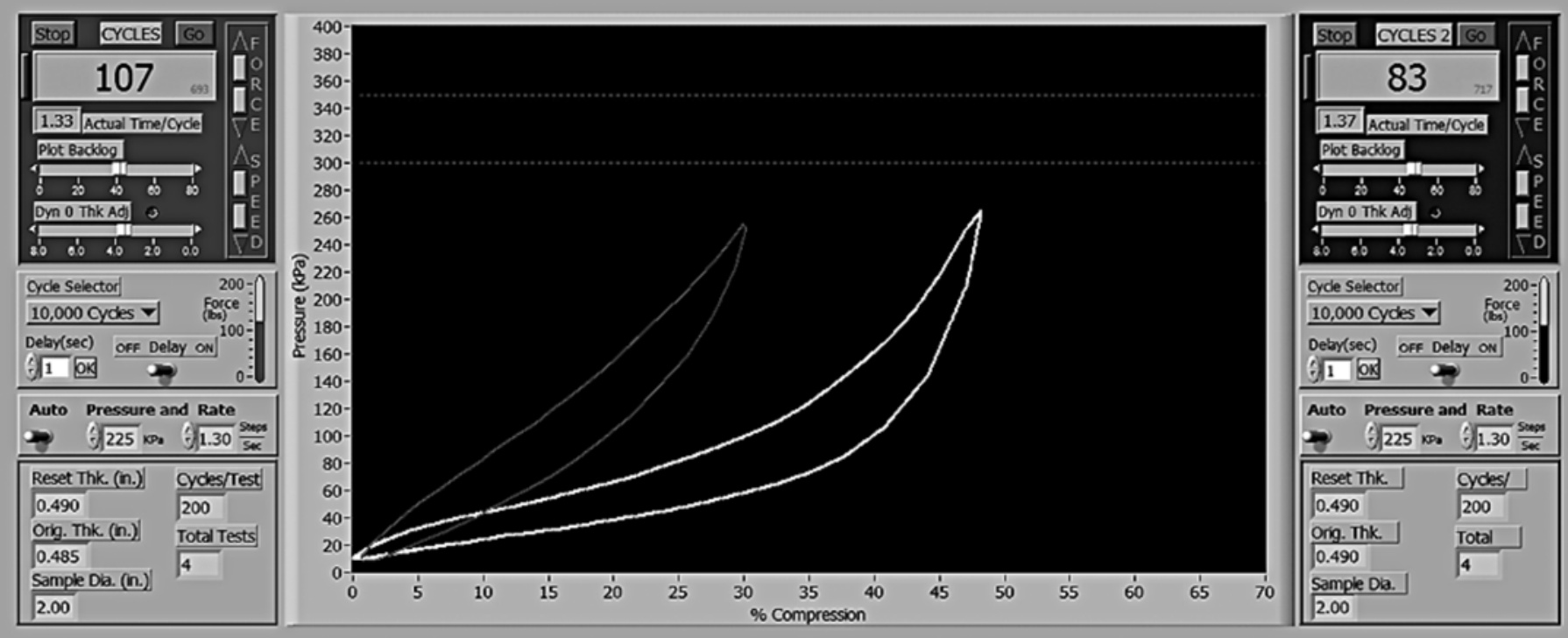

Figure 3.

Cyclical Compression Tester user interface.

recorded between cycles. Before testing, the data are analyzed and graphically interpreted with Microsoft Excel spreadsheet software.

The control system components have four analog input channels, facilitating the simultaneous use of two CCT devices. The control system componentry is housed in a $43.2 \times 33.0 \times 18.7 \mathrm{~cm}$ blow-molded case (Chicago Case Company; Chicago, Illinois). Figure 4 shows the CCT workstations, control system, and computer as they appear in the laboratory.

Calibrated components are essential to the repeatability and reliability of the CCT. Calibration of the load cell is performed with a custom pneumatic device (Figure 5). A $10.2 \mathrm{~cm}$-diameter low-profile air cylinder (Mead Fluid Dynamics; Chicago, Illinois) is mounted to a $10.2 \times 10.2 \times$ $1.3 \mathrm{~cm}$-thick aluminum baseplate. Mounted to the air cylinder piston is a plunger plate on which a factory-calibrated load cell, set as the calibration standard, is placed in series with the targeted load cell used in the CCT. A $6 \mathrm{~mm}$ diameter all-thread rod mounted to the baseplate supports an end beam to back the calibration process. The air supply from a steel portable air tank is electronically controlled by custom software using a two-way air valve
(Humphrey Products Company; Kalamazoo, Michigan) inline to a pressure transducer (MSI Sensors; Hampton, Virginia). The series of calibration pressures are manually controlled by a regulator.

Calibration of the LP is performed by establishing the voltage per centimeter linear relationship between the DC voltage outputs to an analog scale (Starrett Company;

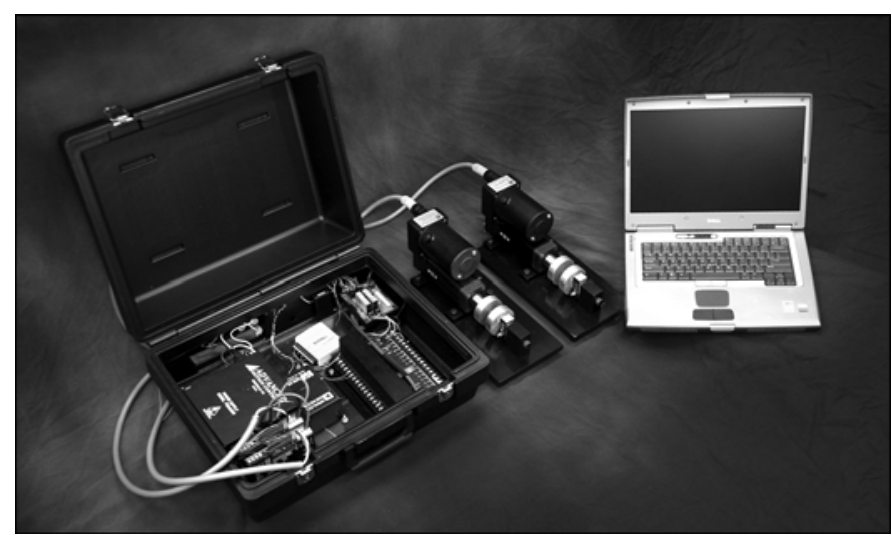

Figure 4.

Cyclical Compression Tester workstation with control system, testing devices, and laptop. 


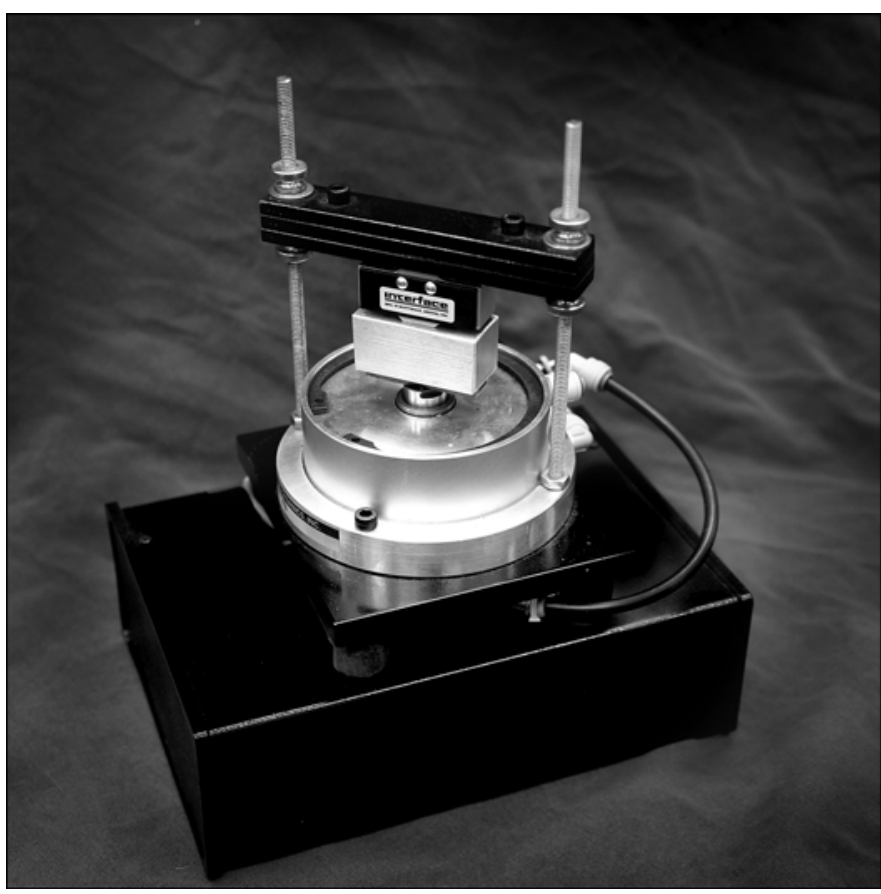

Figure 5.

Custom pneumatic device for calibration of load cells used in Cyclical Compression Tester.

Athol, Massachusetts). A regulated 5 V DC power supply powers the potentiometer circuitry (Omega Engineering, Inc; Stamford, Connecticut).

Before testing, the software interface interactively prompts the user for filename, initial thickness, diameter, number of test cycles per day, and total cycles to be tested. Before all subsequent tests, this information is automatically carried over and the reset thickness variable, measured by the user with a thickness gauge, is provided.

Four single-density materials commonly used in the fabrication of accommodative orthoses were tested [27]: Plastazote 1 (P1) (Zotefoams Inc; Hackettstown, New York), Plastazote 2 (P2) (Zotefoams Inc), Poron (P) (Rogers Corp; Rogers, Connecticut), and Microcel Puff (MP) (Acor Orthopaedic Inc; Cleveland, Ohio). P1 and P2 are closed-cell polyethylene foams of different densities and durometers, $\mathrm{P}$ is an open-cell polyurethane, and MP is a closed-cell ethylene vinyl acetate foam.

Samples $5.1 \mathrm{~cm}$ in diameter and approximately $1.3 \mathrm{~cm}$ thick were prepared for testing. Each material was placed in the CCT, cycled through 10,000 cycles at $300 \mathrm{kPa}$ compressive stress at 1.5 seconds per cycle, and allowed to recover at least 24 hours before testing was resumed.
This process was repeated for 5 days for a total of 50,000 cycles. Two cycles of S-S and DCF were collected every 100 cycles, totaling 200 data points each day. Before and immediately after each test, a caliper thickness gauge was used to measure the material thickness with two decimalpoint accuracy.

The S-S and DCF were graphically monitored during each cycle for all materials. From these measurements, dynamic strain, strain-loss, and DCF were calculated during each cycle. Dynamic strain is the percentage of compression a material experiences with respect to its original thickness while undergoing cyclical stresses and compression rates similar to walking. Strain-loss is the percentage of dynamic strain over time a material loses with respect to its dynamic strain at a new condition, a user-defined set point (UDSP) $\leq 100$ cycles. Dynamic compression fatigue is the ratio, expressed as percentage loss, of the recovered thickness at any time point to the original recovered thickness at the UDSP. The recovered thickness is equivalent to the thickness of the material in the shoe during the foot-swing (no load) phase of gait. Unlike the compression set measured after static loading for a predetermined period (ASTM D 1667), DCF was continuously measured through the 50,000 cycles of compression during simulation of in-shoe conditions. Finally, for each measurement during testing, apparent hardness, energy density, and energy absorption were calculated for each material. Apparent hardness is the instantaneous slope of each point along the S-S curve, energy density is the area under the curve of either the compression or the decompression cycle of S-S, and energy absorption is the difference between the compression and decompression energy density areas.

The custom software allowed for automation of cycle rate (seconds per cycle), stress (force per material surface area), and DCF. The CCT device automatically shut down upon completion.

\section{RESULTS}

The load cell and LP constants, which convert voltage to force and distance, respectively, were determined. The load cell was calibrated and tested in series with the standard from 0 to $90 \mathrm{~kg}$ of force with acceptable congruency $( \pm 0.45 \mathrm{~kg})$. Additionally, the LP was calibrated with acceptable repeatability $( \pm 0.5 \mathrm{~mm})$. A $59 \mathrm{k} \Omega$ precision shunt calibration value, representing 70 percent load, was 
checked before and after daily testing. ${ }^{*}$ The zero and shunt value are calibration checkpoints. If these changed during the course of testing, the load cell was recalibrated.

Samples $5.1 \mathrm{~cm}$ in diameter were tested to maximize the surface area and fit within the $5.5 \mathrm{~cm}$-diameter compression plate design. A $1.3 \mathrm{~cm}$ sample thickness was standardized for reporting. This is a nominal thickness that is readily available and effective for acquiring material properties without compressing beyond the materials' functional strain limits, commonly referred to as "bottoming out." Foto et al. tested 100,000 cycles and determined that plastic deformation of foam materials generally begins after 10,000 cycles [22]. The authors chose 50,000 cycles to accomplish plastic deformation to any applicable materials tested.

For 5 consecutive days, each material was tested for 10,000 cycles, which lasted approximately 4 hours per day. Testing concluded after 50,000 cycles on the fifth day. The data were analyzed with a custom macro in a spreadsheet environment. For mathematical modeling of the material properties and wear characteristics, a least squares numerical routine was used to derive the coefficients of a sixth-order polynomial equation from an array of S-S data of the particular material tested. Numerical differentiation and integration of this polynomial equation provided the apparent hardness and energy density characteristics of the material. These three numerical models (S-S, apparent hardness, and energy density) describe the state of the material from which to base predictive behavior.

Figures 6 and 7 show the uniaxial compression curve of the four materials at 100 and 50,000 cycles, respectively. At 100 cycles, the MP material showed the least dynamic strain at 28 percent, while $\mathrm{P}$ showed the greatest at 54 percent. At 50,000 cycles, MP and P2 showed the least dynamic strain at 22 percent, while $\mathrm{P}$ showed the greatest at 52 percent. P1 showed the greatest strain loss at 38 percent, while $\mathrm{P}$ showed the least at 4 percent. The greater the dynamic strain, the more accommodative the material; the lower the strain loss, the more durable the material.

DCF was analyzed over repetitive cycles. This characteristic of a material is recognized by monitoring excursion (in millimeters) along the strain axis of the no-

\footnotetext{
*Vishay Measurements Group, Shunt calibration of strain gauge instru-
} mentation, Tech Note TN-514, < www.vishay.com>.

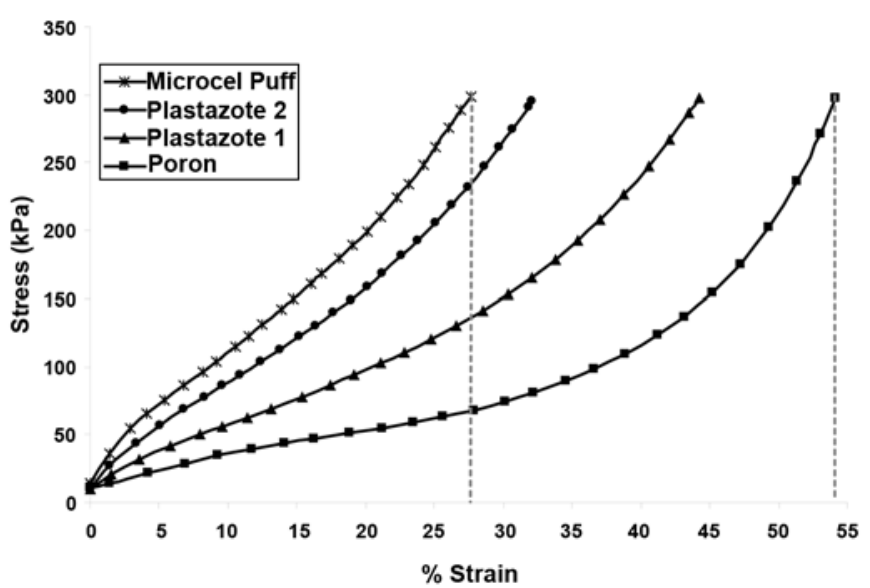

Figure 6.

Uniaxial compression at 100 cycles for Microcel Puff, Plastazote 1, Plastazote 2, and Poron.

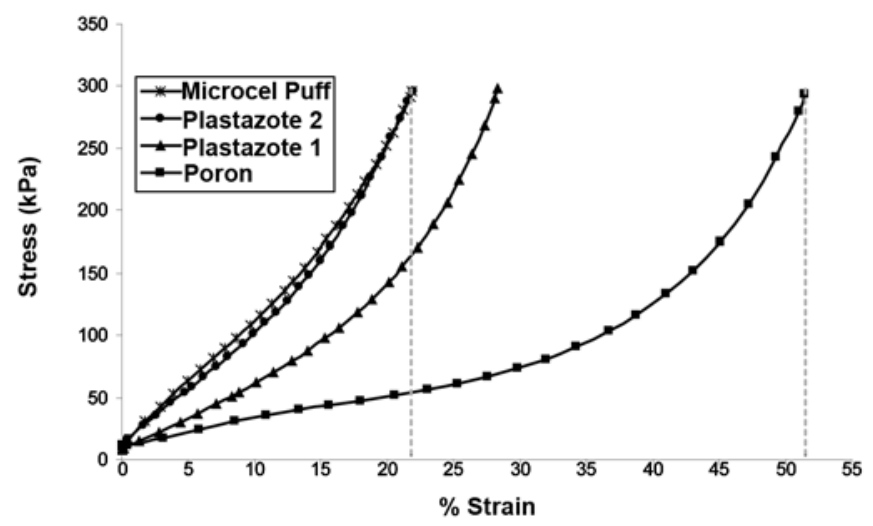

Figure 7.

Uniaxial compression at 50,000 cycles for Microcel Puff, Plastazote 1, Plastazote 2, and Poron.

load point of the S-S curve from the origin throughout testing. These data are reduced to the actual working thickness of the material. Working thickness is defined as the between-step reset thickness of the material preloaded by laced footwear and is always less than the nominal thickness. The CCT preloads the material at $2 \mathrm{~kg}$, as defined in the graphical user interface. Figure 8 shows percentage losses of actual working thickness of 25 and 8 percent for P2 and P, respectively. Nominal versus actual working thickness is an important variable when one is dealing with therapeutic footwear for persons with 


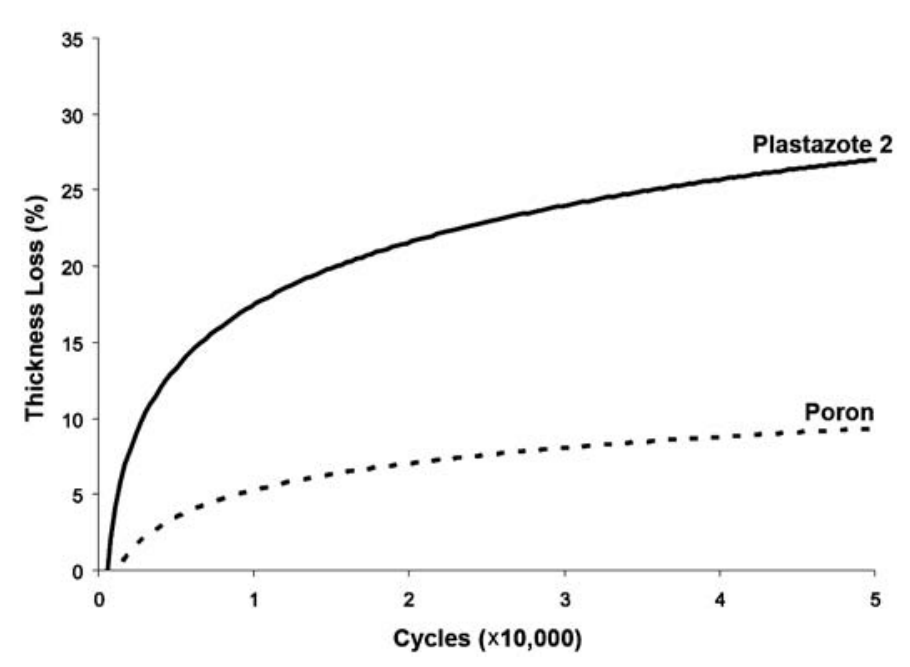

Figure 8.

Percentage loss in material due to dynamic compression fatigue.

peripheral neuropathy. DCF plotted against total cycles is a material performance curve not reported in previous research and is obtainable through the custom algorithm interfaced to the CCT.

\section{DISCUSSION}

A digitally controlled, benchtop material tester is described in this technical article. The application for such a device extends from the clinician who is responsible for deciding the useful life of single- and multidensity orthosis materials to the researcher who characterizes materials for finite element analysis modeling. While this device does not replace subject testing, it does greatly reduce the clinician time and patient risk involved in determining applicable material properties and predicting performance. The effect of heat and perspiration was not considered in this study and is beyond the scope of this device.

Analysis of the data provided information unavailable by any previous research to date. While S-S curves have been provided by previous authors, data throughout the entire testing period, including dynamic compression fatigue, were not previously available. Additionally, numerical analysis of the data allows for the differentiation and integration of the S-S curve. Differentiation gives the instantaneous slope of each point, indicating the apparent hardness of the material [26]. Integration gives the area under the S-S curve, providing a progressive magnitude of energy density and energy absorption of the material compared with its UDSP. Manipulating the variables' units of stress and strain after numerical integration results in energy per volume (Newton-meter per cubic meter) and, hence, energy density. The difference between the energy density magnitude of a tested material's compression and decompression cycle is the energy absorption. These properties are useful in material selection for a particular application or level of activity and may provide information that can be extrapolated to inshoe conditions.

The CCT was created as a portable desktop device to evaluate single- or multidensity materials in comparison with the performance of other materials. Sanders et al. [26], using their custom device, demonstrated similar S-S data for P and P1. Although the S-S data of the materials tested have not been compared with a commercial servocontrolled mechanical tester, the implementation of the calibration method, as previously outlined, provides for reliable data generation and comparative analysis and can be universally applied to any such system.

The cost to fabricate the dual station CCT was roughly $\$ 5,500$ for mechanical and electronic hardware, frame materials, and labor. All mechanical and electronic components are commercially available stock items. The structural materials are nominal sized for minimal machining and ease of construction.

\section{CONCLUSIONS}

This real-time CCT device, custom user interface, and load cell calibrator combine to make an evaluation tool useful for testing how pressure distribution of inshoe materials changes over time in therapeutic footwear for those with peripheral neuropathy at risk for foot injury.

\section{ACKNOWLEDGMENTS}

This material is the result of work supported with resources and the use of facilities at the National Hansen's Disease Programs, Paul W. Brand Biomechanics Laboratory. 
JRRD, Volume 45, Number 6, 2008

The author has declared that no competing interests exist.

\section{REFERENCES}

1. Birke JA, Sims DS. Plantar sensory threshold in the ulcerative foot. Lepr Rev. 1986;57(3):261-67. [PMID: 3784758]

2. Zhu H, Wertsch JJ, Harris GF, Alba HM, Price MB. Sensate and insensate in-shoe plantar pressures. Arch Phys Med Rehabil. 1993;74(12):1362-68. [PMID: 8259906]

3. Stess RM, Jensen SR, Mirmiran R. The role of dynamic plantar pressures in diabetic foot ulcers. Diabetes Care. 1997; 20(5):855-58. [PMID: 9135955]

4. Chantelau E, Kushner T, Spraul M. How effective is cushioned therapeutic footwear in protecting diabetic feet? A clinical study. Diabet Med. 1990;7(4):355-59.

[PMID: 2140090]

5. Uccioli L, Faglia E, Monticone G, Favales F, Durola L, Aldeghi A, Quarantiello A, Calia P, Menzinger G. Manufactured shoes in the prevention of diabetic foot ulcers. Diabetes Care. 1995;18(10):1376-78. [PMID: 8721941]

6. Perry JE, Ulbrecht JS, Derr JA, Cavanagh PR. The use of running shoes to reduce plantar pressures in patients who have diabetes. J Bone Joint Surg Am. 1995;77(12):1819-28. [PMID: 8550649]

7. Kästenbauer T, Sokol G, Auinger M, Irsigler K. Running shoes for relief of plantar pressure in diabetic patients. Diabet Med. 1998;15(6):518-22. [PMID: 9632129]

8. Mueller MJ, Strube MJ, Allen BT. Therapeutic footwear can reduce plantar pressures in patients with diabetes and transmetatarsal amputation. Diabetes Care. 1997;20(4): 637-41. [PMID: 9096994]

9. Birke JA, Foto JG, Pfiefer LA. Effect of orthosis material hardness on walking pressure in high-risk diabetes patients. J Prosthet Orthot. 1999;11(2):43-46.

10. McPoil TG, Cornwall MW. Effect of insole material on force and plantar pressures during walking. J Am Podiatr Med Assoc. 1992;82(8):412-16. [PMID: 1507079]

11. Ashry HR, Lavery LA, Murdoch DP, Frolich M, Lavery DC. Effectiveness of diabetic insoles to reduce foot pressures. J Foot Ankle Surg. 1997;36(4):268-71; discussion 328-29. [PMID: 9298441]

12. Viswanathan V, Madhavan S, Gnanasundaram S, Gopalakrishna G, Das BN, Rajasekar S, Ramachandran A. Effectiveness of different types of footwear insoles for the diabetic neuropathic foot: A follow-up study. Diabetes Care. 2004;27(2):474-77. [PMID: 14747231]

13. Tsung BY, Zhang M, Mak AF, Wong MW. Effectiveness of insoles on plantar pressure redistribution. J Rehabil Res Dev. 2004;41(6A):767-74. [PMID: 15685465]
14. Cook SD, Kester MA, Brunet ME. Shock absorption characteristics of running shoes. Am J Sports Med. 1985;13(4): 248-53. [PMID: 4025676]

15. Baumann W, Krabbe B, Galbierz P. Life characteristics of running shoes and shoe material. In: Proceedings of the 2nd Symposium of the International Society of Biomechanics Working Group on Functional Footwear; 1995 Jun 28-30; Cologne, Gemany. p. 38-39.

16. Shiba N, Kitaoka HB, Cahalan TD, Chao EY. Shockabsorbing effect of shoe insert materials commonly used in management of lower extremity disorders. Clin Orthop Relat Res. 1995;(310):130-36. [PMID: 7641428]

17. Lewis G, Tan T, Shiue YS. Characterization of the performance of shoe insert materials. J Am Podiatr Med Assoc. 1991;81(8):418-24. [PMID: 1920103$]$

18. Valiant GA, Kilgore BJ, Tawney J, McMahon TA. Development of a new running shoe cushioning technology. In: Proceedings of the 5th Symposium on Footwear Biomechanics; 2001; Zurich, Switzerland. p. 78-79.

19. Armstrong DG, Lavery LA, Harkless LB. Who is at risk for diabetic foot ulceration? Clin Podiatr Med Surg. 1998; 15(1):11-19. [PMID: 9463765]

20. Perell KL, Merrill V, Nouvong A. Location of plantar ulcerations in diabetic patients referred to a Department of Veterans Affairs podiatry clinic. J Rehabil Res Dev. 2006; 43(4):421-26. [PMID: 17123181]

21. Cavanagh PR, Ulbrecht JS. Biomechanics of the foot in diabetes mellitus. In: Levin ME, O’Neal LW, Bowker JH, editors. The diabetic foot. 5th ed. St. Louis (MO): Mosby Year Book; 1993. p. 199-232.

22. Foto JG, Birke JA. Evaluation of multidensity orthotic materials used in footwear for patients with diabetes. Foot Ankle Int. 1998;19(12):836-41. [PMID: 9872471] Erratum in: Foot Ankle Int. 1999;20(2):143.

23. Campbell GJ, McLure M, Newell EN. Compressive behavior after simulated service conditions of some foamed materials intended as orthotic shoe insoles. J Rehabil Res Dev. 1984;21(2):57-65. [PMID: 6530678]

24. Brodsky JW, Kourosh S, Stills M, Mooney V. Objective evaluation of insert material for diabetic and athletic footwear. Foot Ankle. 1988;9(3):111-16. [PMID: 3229697]

25. Petre MT, Erdemir A, Cavanagh PR. Determination of elastomeric foam parameters for simulations of complex loading. Comput Methods Biomech Biomed Engin. 2006; 9(4):231-42. [PMID: 17132531]

26. Sanders JE, Greve JM, Mitchell SB, Zachariah SG. Material properties of commonly-used interface materials and their static coefficients of friction with skin and socks. J Rehabil Res Dev. 1998;35(2):161-76. [PMID: 9651888]

27. Foto JG, Birke JA. Who's using what: An orthotic materials survey. BioMechanics. 1996;3(7):63-68.

Submitted for publication July 23, 2007. Accepted in revised form January 14, 2008. 